\title{
Understanding teenage fertility in Peru: an analysis using longitudinal data
}

\begin{abstract}
Reducing the prevalence of teenage pregnancy remains an elusive goal for public policy in Peru. We use longitudinal data from the Young Lives Study in Peru to investigate on an extensive set of early circumstances and life changes that might be risk factors of teenage childbearing-about 1 out of 5 females in the sample were teenage mothers. The use of longitudinal data allows us to alleviate methodological concerns common to this type of analysis. According to our results, growing up in a poor household, in a single parent household, leaving school at or before age 15, bad school performance at age 12, and having the first sexual relation at age 16 or under are key risk factors of early childbearing. From a time-varying perspective, we uncover the importance of changes in child and household characteristics that occurred prior to childbearing. Among other factors, we find that improvements in self-efficacy and in education aspirations during adolescence are associated with a decrease in the probability of early childbearing. Risk factors identified are considerably more relevant -in most cases, only relevant- for females. From a policy perspective, our results suggest that initiatives aimed at improving school attendance, sexual education, and socioemotional competencies among adolescents might be effective tools to reduce the high rates of teenage pregnancy in Peru.
\end{abstract}

Keywords: Teenage fertility, Peru, Young Lives, longitudinal data.

JEL Codes: D1, I3, J1 


\section{Introduction}

According to the 2012 World Bank report on teenage pregnancy, the Latin American and Caribbean region has the third highest teenage fertility rate on the globe after Sub-Saharan Africa and South Asia (Azevedo et al., 2012). Teenage childbearing has progressively become a major policy concern, as the majority of studies point to a negative impact (although with significant differences in magnitude) of early fertility on parents' (mainly on mothers') outcomes and on the birth and future of the newborns (Geronimus et al., 1994; Francesconi, 2008; Levine et al., 2001; Lopez Turley, 2003; Ashcraft and Lang, 2006).

The social science and public health literature highlight the role of socioeconomic background, education, sex knowledge and family planning policies as some of the main determinants of early pregnancy in developing countries (Acharya et al., 2010; Azevedo et al., 2012; Pradhan et al., 2015; Magadi, 2017). Nevertheless, there is still a lot to learn about what are the factors that over the life course determine the occurrence of early childbearing. Socio-emotional aspects and changes in life circumstances, which are typically unobserved, might play a substantial role in explaining this outcome. Many of these aspects have not been studied in developing countries due to data limitations. Furthermore, most of the studies available for developing countries are based on cross-sectional data (Pradhan et al., 2015), and, thus, results are likely to be at least partly afflicted by reverse causality bias.

This paper intends to contribute to the literature that investigates the occurrence of teenage pregnancy in developing countries in three ways. First, we deal with reverse causality by using longitudinal data. Compared to studies based on standard cross-sectional surveys (e.g., Demographic and Health Surveys), we exploit information collected for the same cohort through their life course, from childhood to late adolescence. Second, we go beyond the traditional factors commonly studied in the literature and incorporate into the analysis the role of early family characteristic, school achievement, socio-emotional competencies, aspirations, and parental expectations as drivers of early 
fertility. We also look at the role of changes in individual and household characteristics over time. This helps to partially deal with omitted variable bias. Third, we investigate differences in drivers for teenage parenthood among females and males.

According to the official statistics, 14 per cent of female teenagers have had at least one child born alive between the age 15 and 19 in Peru. What is particularly striking is that, despite the fact that poverty has substantially reduced in Peru during the last years (from 54 per cent in 2002, to 21 per cent in 2017), the prevalence of teenage pregnancy has remained surprisingly high and constant over the same period, having regions with rates of teenage pregnancy above 30 per cent.

We use longitudinal data from the Young Lives Survey in Peru, a unique individual-level panel following a cohort of about 635 children between ages 8 and 19. In this sample, 1 out of 5 females had a child at age 19 (similar to the national average at that age), whereas 1 out of 20 males had a child at the same age. The richness of the Young Lives survey allows us to investigate the role of multiple factors that might affect these outcomes for both females and males. The analysis is structured considering risk factors observed during three stages of the life-cycle: mid-childhood (household socio-demographic characteristics and family structure), early adolescence (school achievement, socioemotional competencies and aspirations, and parental expectations) and midadolescence (school enrolment, knowledge of family planning methods, and sexual behaviours). All of these aspects are observed prior to the outcome of interest. We also look at how changes in sociodemographic characteristics (including changes in wealth and migration), changes in family structure (parental absence) as well changes in aspirations, school achievement, and socioemotional competencies, might have affected the probability of teenage childbearing. 


\section{Literature review}

This section provides a brief and non-exhaustive review of the literature that investigates the determinants of early pregnancy, predominantly - but not exclusively - in developing countries.

Low socioeconomic status is regularly identified as one of the main risk factors for teenage childbearing (Acharya et al., 2010; Azevedo et al., 2012; Pradhan et al., 2015; Magadi, 2017; Maness, et al., 2016; Hobcraft and Kiernan, 2001). This association might be driven by the perceived opportunity cost, i.e. by the fact that the cost of early childbearing is lower for poorer families (due to low access to school, low aspirations or the need of working at home) than for wealthier families. Nevertheless, poor adolescents are also likely to be vulnerable in other dimensions that can trigger teenage pregnancy, some of which are often unobserved. Socioeconomic context might constrain adolescents' behaviours by shaping perceptions, attitudes and values that ultimately guide behavioural choices, such as sexual behaviours and contraceptive use (Brewster et al., 1993). Other socioeconomic factors that are highly correlated with teenage pregnancy are parental education (Young et al., 2004; Brewster et al., 1993; Azevedo et al., 2012), interpersonal family experiences, such as exposure to parental separation and having a teen mother (Quinlivan, 2004; Margherita et al., 2017), and living in communities with limited access to good public services.

Virtually all studies highlight the critical role of education in delaying early fertility. Furthermore, some highlight the role of educational expectations and confidence in educational achievement in the probability of early childbearing (Young et al., 2004). In addition, the age of sexual initiation, sexual behaviours (Nüñez and Flórez, 2001; Were, 2007; Azevedo et al., 2012; Pradhan et al., 2015; De Genna et al., 2011), and specific knowledge of sexual and reproductive health (Were, 2007; Pradhan et al., 2015) are strongly linked to teenage fertility.

Some of the aforementioned associations are observed in a multivariate regression framework. Azevedo et al. (2012) used Demographic and Household Survey (DHS) data from six Latin American countries, including Peru. They found that adolescent girls from urban areas and from 
wealthier families are less likely to be teenage mothers. They also observed a higher incidence of teenage childbearing among girls who had their first sexual experience at younger ages, who did not make regular use of any contraceptive method, and especially those who did not use any contraception during their first sexual experience (see also Nuñez and Florez, 2001). Similarly, a systematic review for developed countries (Imamura et al., 2007) showed that the most consistent risk factor for early pregnancy were lower socioeconomic status, as well as family disruption.

Noticeably, all papers cited to this point show pure correlations. Only a few studies identify the causes of teenage parenthood, using exogenous variations in the supply of contraceptives and abortion laws as an identification strategy. Some examples of this strategy - that used data from the United States - are Lundberg and Plotnick (1995) and Kane and Staiger (1996). Lundberg and Plotnick (1995) found that the presence of accessible family planning services reduces the probability of premarital pregnancy, while Kane and Staiger (1996) found that restricting access to abortion has no clear effect on teen birth rates. In a more recent study, Ananat and Hungerman (2012) exploited geographical variation in the introduction of oral contraceptives (the pill) in the United States. They found that the introduction of the pill was responsible for a decline in the fertility of unmarried women under 21.

Finally, a growing body of the economics literature has been making inferences about the role of subjective expectations for fertility behaviours and early childbearing. For example, Plotnick's empirical studies (Plotnick, 1992, 1993; Plotnick et al., 2007) in the United States and the United Kingdom showed that teenagers' positive attitudes and expectations about their future reduce the probability to get pregnant during adolescence. They argued that adolescents with higher opportunity costs, indicated by better grades and higher expectations and aspirations for their schooling, expect and desire to marry and have children at older ages. Similar, Rascon-Ramirez (2014) showed that high parental expectations about their children's education decrease the likelihood of teenage pregnancy and motherhood in the United Kingdom. 


\section{Dat a}

This paper uses the Peruvian sample of the Young Lives Survey, a unique individual-level panel dataset that follows two cohorts of children in Ethiopia, India (Andhra Pradesh and Telangana), Peru, and Vietnam for more than a decade and five rounds of data collection. The younger cohort was born in 2001/02, aged around 1-year-old at the time of the first round in 2002 and 15 years old when interviewed for the last time in 2016. In this paper, we use the first four rounds of data for the older cohort, born in 1994/95 and aged around 8 years old in Round 1, 12 years old in 2006, 15 years old in 2009, and 19 years old in Round 4. Almost 90 per cent of the older cohort children in the study sample in 2002 were interviewed in Round 4. Specifically, the attrition rate over the 12-year period of data collection was about $10.3 \%$, which is relatively low compared to many longitudinal studies in developing countries.

The older cohort sample for Peru gathers information for approximately 635 individuals (index children), spread over 20 sentinel sites in different geographical regions. The sampling design purposely over-sampled poor areas. Twenty clusters were randomly selected from the complete list of districts in Peru in 2002, excluding the wealthiest 5\%. Each cluster was given a probability of being selected that was proportional to its population size. Then, within each selected cluster, an area was randomly selected and families with children aged 6 to 18 months and 7 to 8 years were selected to be part of the younger and older cohort, respectively. Although Young Lives is not intended to be representative of the country as a whole, because of the sampling procedure used, the Young Lives sample for Peru has been found to optimally reflect the diversity of children and families in Peru, excluding the wealthiest 5\%. For more details about the sampling design, see Escobal and Flores (2008).

The survey collects information through a face-to-face interview with the main caregiver (household questionnaire), and with the index child (child questionnaire). In addition, a selfadministered questionnaire (SAQ) is completed by the index child in Rounds 3 and 4 . The SAQ is 
intended to gather information that is considered "sensitive" (such as information about risky behaviours: drug, alcohol, or cigarette consumption, engagement in illegal and violent activities, and sexual behaviours), in order to guarantee the child full confidentiality and minimise the risk of potential under- and misreporting. The main variables of interest in our analysis come from the household and child questionnaires, with the exception of the variables related to sexual behaviours, contraceptive use, and information about sexual and reproductive health, which come from the SAQ. Descriptive statistics of the sample are reported in Table 1 (for the balanced sample of children observed across all rounds and with non-missing data, 483 individuals).

Childbearing is defined using information from the child questionnaire collected when the sampled individual was 19 years old. More specifically, early childbearing is a dummy variable defined based on the following question: "How many times have you given birth during your life?" Both males and females were asked this question. Using this information, we find that 12 per cent of the balanced sample (the reference sample here onwards) had a child at the age of 19. Although equivalent questions were not asked in the previous round (when individuals were 15 years old), based on the date of the interview and the date of birth of the first child, we calculate that 95 per cent of the cases of early childbearing observed in the data (55 out of 58) occurred between the last two rounds of data collection, i.e., between ages 15 and 19. This means that the data collected up to round 3 (at age 15) was collected prior to childbearing.

Prevalence of childbearing by gender, area of location and wealth are reported in Table 2. Around 21 per cent of females in the sample are teenage mothers at the age of 19. In contrast, only 5 per cent of males report having a child at that age. No significant differences based on area of location (urban or rural) emerge using the Young Lives data, which might result from the sampling design and the small sample size within rural areas. On the other hand, our data suggests 
a higher prevalence of teenage parents among the poorest segment of the population. This difference is not statistically significant.1

\section{Methods}

Our aim is to study the risk factors of early childbearing in Peru using data collected during the first three visits to the older cohort (in 2002, 2006 and 2009). We distinguish between factors observed during mid-childhood (age 8), early-adolescence (age 12) and mid-adolescence (age 15). Since 95 percent of teenagers that became parents conceived their children after the third visit, for the vast majority these characteristics can be treated as predictors in a statistical sense. 2 Denote the probability that individual $i$ born in cluster $j$ had a child or was pregnant during adolescence as $\mathrm{P}\left(Y_{\mathrm{ij}}=1 \mid \mathbf{Z}_{\mathrm{i}}, \mathbf{X}_{\mathrm{i}}\right)$, measures in the fourth visit (2013). We assume the following (linear probability) baseline model:

$$
\mathrm{P}\left(Y_{\mathrm{ij}}=1 \mid \mathbf{Z}_{\mathrm{i}}, \mathbf{X}_{\mathrm{i}}\right)=\gamma_{0}+\mathbf{Z}_{\mathrm{i}} \boldsymbol{\Gamma}_{1}+\boldsymbol{C}_{\mathrm{i}} \boldsymbol{\Gamma}_{2}+\boldsymbol{E} \boldsymbol{A}_{\mathrm{i}} \boldsymbol{\Gamma}_{3}+\boldsymbol{M} \boldsymbol{A}_{\mathrm{i}} \boldsymbol{\Gamma}_{4}+\omega \mathrm{j}+\epsilon_{\mathrm{i}}
$$

where $\mathbf{Z}_{\mathrm{i}}$ is a vector that accounts for sex and age in years at the exact time teenage parenthood was measured; $\boldsymbol{C}_{\mathrm{i}}$ incorporates the role of factors observed during mid-childhood (age 8 ) or that can be treated as time-invariant; $\boldsymbol{E} \boldsymbol{A}_{\mathrm{i}}$ and $\boldsymbol{M A}$ i, stand for factors observed during early adolescence (age 12) and mid-adolescence (age 15), respectively; $\omega_{\mathrm{j}}$ is a cluster fixed effect, which allows us to control for observed or unobserved cluster characteristics that are fixed over time; and, $\epsilon_{i}$ is the error term. Specifically, vector $\boldsymbol{C}_{\mathrm{i}}$ incorporates the role of household socio-demographic characteristics (area of residence, household wealth3, maternal level of education) and household

1 In fact, the difference in prevalence of teenage parents across wealth index is not significantly different from zero when considering female and male teen parents together while is statistically significant at the $5 \%$ level among girls. 2 According to our estimates, only 2 females (out of 46) and 1 male (out of 12) had a child when visited in 2009 at the age of 15 .

3 Measured through the household wealth index-a composite measure of living standards including housing quality, access to services, and a consumer durables index (Briones, 2017). 
structure (number of siblings, whether the individual has an older brother, an older sister, was raised in a single-parent household, and born to a teenage mother); vector $\boldsymbol{E A}_{\mathrm{i}}$ incorporates the role of the following factors: school achievement (numeracy and vocabulary knowledge test $\mathrm{z}-$ scores), socio-emotional competencies and aspirations (self-esteem and self-efficacy z-scores, aspirations for higher education), parental expectations (expected age of marriage, having a baby and leaving full-time education), and whether the individual reached puberty by age 12 ; finally vector $\boldsymbol{M A}$ i incorporates the role of school enrolment, 4 knowledge about sexual and reproductive, and sexual behaviours (whether the individual was 16 years old or under when first engaged in sexual intercourse, and had unprotected sex before the age of 15).5 The definition of these variables are reported in Table A1 in the Online Appendix.

Although in some cases the age-period in which variables are measured is constrained by data availability,6 vectors $\boldsymbol{C}_{\mathrm{i}}, \boldsymbol{E} \boldsymbol{A}_{\mathrm{i}}$ and $\boldsymbol{M} \boldsymbol{A}_{\mathrm{i}}$ have been constructed to orderly introduce aspects that either start becoming important only, or become specially important at, certain ages, including the role of childhood poverty (captured by household wealth and area of residence at age 8), the role of competencies acquired throughout childhood and adolescence (captured by school achievement, socio-emotional competencies, and aspirations at age 12), the role of school enrolment (which varies meaningfully at age 15), and the role of sexual knowledge and behaviours.

The baseline model does not consider the role of time-changing factors, however between 2002 and 2009, there was substantial migration to urban areas, changes in socio-economic characteristic and in household structure in the sample. Similarly, it is expected that individual circumstances

\footnotetext{
4 While information about school enrolment are available since earlier ages, school attendance is close to universal at age 12 and it only starts decreasing once children start transiting the secondary-level education.

5 The information about sexual knowledge and sexual behaviors was collected through a self-administered questionnaire.

6 Self-esteem, self-efficacy, aspirations, test scores in numeracy and vocabulary knowledge, and parental expectations were measured for the first time at age 12; sexual knowledge and behaviours, at age 15 .
} 
might have changed during adolescence, all of which with potential implications for teenage pregnancy. We estimate an extended model, defined as follows:

$$
\begin{aligned}
Y_{\mathrm{ij}, 19}=\gamma_{0} & +\mathbf{Z}_{\mathrm{i}} \boldsymbol{\Gamma}_{1}+\boldsymbol{C}_{\mathrm{i}} \boldsymbol{\Gamma}_{2}+\boldsymbol{E} \boldsymbol{A}_{\mathrm{i}} \boldsymbol{\Gamma}_{3}+\boldsymbol{M} \boldsymbol{A}_{\mathrm{i}} \boldsymbol{\Gamma}_{4} \\
& +\Delta \boldsymbol{C}_{\mathrm{i}, \mathrm{MA}-\mathrm{C}} \boldsymbol{\Gamma}_{5}+\Delta \boldsymbol{E} \boldsymbol{A}_{\mathrm{i}, \mathrm{MA}-\mathrm{EA} \boldsymbol{\Gamma}_{6}+\omega \mathrm{j}+\epsilon_{\mathrm{i}, 19}}
\end{aligned}
$$

where vector $\Delta \boldsymbol{C}_{\mathrm{i}, \mathrm{MA}-\mathrm{C}}$ introduces the following changes between mid-childhood and midadolescence: (i) household socio-demographic characteristics -changes in household wealth; rural-urban and rural-urban migration; (ii) household structure -changes in parental presence (whether the parents split or the parents split and regrouped again/a new family was formed); changes in the number of siblings in the household; and vector $\Delta \boldsymbol{E} \boldsymbol{A}_{\mathrm{i}, \mathrm{MA}-\mathrm{EA}}$ incorporates the following changes between early and mid-adolescence: (i) school achievement -changes in numeracy and vocabulary knowledge z-scores; (ii) socio-emotional competencies -changes in self-esteem and self-efficacy z-scores; (iii) aspirations for higher education -reducing or improving aspirations (downward or upward aspirations, respectively). In order to estimate this model, some categorical variables in levels were re-defined to obtain results that are easier to interpret.7

The models are estimated for the full sample. In addition, to test whether the associations between the selected determinants and the outcomes of interest differ by gender, we estimate a fully interacted model by gender.

7 In particular, (i) the urban dummy at the age of 8 was replaced by a always live in an urban area at age 8 and 15 dummy; (ii) the single-parent household dummy at the age of 8 was replaced by an always single-parent household at age 8 and 15 dummy; and, (iii) the child aspires for higher education was replaced by a dummy that takes the value of 1 if the child has persistently low aspirations at age 12 and 15, 0 otherwise. 


\section{Results}

\subsection{Baseline model}

In Table 3, we report the estimates for the model specification corresponding to equation (1).

Only those variables that are statistically significant are reported. Panel (A) and Panel (B) report results excluding and including the role of sexual and reproductive health $(\mathrm{SRH})$ knowledge and sex behaviours. We do a separate reporting of these specifications for sample size considerations (SRH knowledge and sex behaviours information come from the self-administered questionnaire, a separate survey module with a lower rate of response).8 Results are reported for the full sample (column (i)) and then for the fully interacted model, assuming constant coefficients by gender and interacting all of the selected risk factors by a gender dummy that takes the value of 1 if the individual is female (column (ii)). In column (iii) we report the total estimated coefficient for the female sample, to facilitate the interpretation of the fully interacted model. Notably, interacted models explain a much larger portion of the variance in the outcomes of interest (adjusted R-squared of $12 \%$ and 34\% in Panels (A) and (B), respectively), suggesting that gender plays an important role in how the selected predictors correlate to the outcomes.

Focusing on Panel (A), when considering the constant coefficients model, we find that aging from 18 to 19 years increases the probability to become a parent during adolescence by 7 percentage points (pp), whereas being female is associated with an increase of $16 \mathrm{pp}$ in the probability of early childbearing. School attendance at age 15 reduces the probability of early childbearing by $15 \mathrm{pp}$. It might appear surprising that other factors do not seem to play a role, especially aspects related to household socio-economic characteristics, commonly identified in the literature as important risk factors for early childbearing. However, a different picture emerges when distinguishing by gender.

8 From our sample of interest (individuals that answered questions in all rounds of data collection), there were 63 individuals that did not answer the self-administered questionnaire at age 15 . In order to maximize precision, in column (i) we report results for the largest sample size available. Point estimates of this model remain virtually unchanged when re-estimating it for the sample for which SHR knowledge and sex behaviours at age 15 are observed. 
Moving to the interacted coefficients model, the most striking aspect that emerges is that most factors are considerably more relevant and, in many cases, are only relevant for females. Looking at the role of household socio-economic characteristics measured in the mid-childhood period, the association with the wealth index is only relevant for females, with a marginal effect that more than double (in absolute value) the one observed in the model without gender interactions. An increase in the household wealth index of one standard deviation at the age of 8 would reduce the probability of early childbearing for females by $50 \mathrm{pp}$.

When assessing the role of aspects measured in the adolescence period, we observe that an increase of one standard deviation in the vocabulary test score at the age of 12 reduces the risk of childbearing for females by $7 \mathrm{pp}$. Similarly, school attendance at age 15 reduces the probability of early childbearing for females by $32 \mathrm{pp}$. The fact that school attendance stands as statistically significant even when the estimation controls for proxies of cognitive and non-cognitive skills suggests that merely attending school might be a buffer for teenage childbearing.

Differences by gender are reported in the third column of Panel (A). Looking at the role of household characteristics observed during mid-childhood, it is found that living in a single-parent household at age 8 reduces the probability of early childbearing by $6 \mathrm{pp}$ for males, whereas it has the opposite effect on females increasing this probability by approximately $10 \mathrm{pp}$. While cautious is needed in interpreting these last results given the loss in precision of the estimate for females, our results would confirm the importance of family structure for females. No further gender differences are observed related to the role of factors observed during early and mid-adolescence.

Most of the previous results hold when the role of SHR knowledge and sex behaviours is introduced (Panel (B)), which reduces sample size. A few variables change its statistically significance but point estimates remain very similar to those reported in Panel (A), suggesting that the key difference is that the full-model specification allows for more precise estimates. Along these lines, considering results from the constant coefficients model, some coefficients associated to 
household characteristics measured during the mid-childhood period become statistically significant: a one standard deviation increase in the household wealth index reduces the probability of early childbearing by $23 \mathrm{pp}$, whereas the number of siblings is negatively associated with the probability of childbearing at age 19. In the case of the interacted coefficients model, having an older brother is found to increase the probability of early pregnancy for females by $9 \mathrm{pp}$.

Furthermore, comparing results from Panel (A) and Panel (B), the key difference is that there is a dramatic change in the coefficient associated with school attendance (it decreases by half and becomes statistically insignificant in the constant coefficients model; an even more pronounced change is observed for females). This difference is not driven by the change in the sample.9 In parallel, we found that having had sex at age 16 or under increases the probability of early childbearing by $25 \mathrm{pp}$, and specifically by $7 \mathrm{pp}$ for males and by $55 \mathrm{pp}$ for females, while neither SHR knowledge nor the occurrence of unprotected sex predict early childbearing. In other words, there seems to be an association between school attendance and the age of sexual initiation, an aspect that is further discussed in the next section.

\subsection{Extended model}

The results of Equation (2) - the extended model that incorporates time-changing factors - are reported in Table 4 for the constant coefficients model (column (i)) and the interacted coefficients model (column (ii)); the marginal effects for females resulting from the interacted coefficients model are reported in column (iii). As before, only variables that are statistically significant are reported. For samples size considerations, Panel (A) reports analogous results to Panel (B) but excluding the SHR knowledge and sex behaviours controls. Unless otherwise specified, from here onwards 
we comment results for the interacted coefficients model with the full specification (Panel (B), columns (ii) and (iii)).

Overall, most of the previous conclusions about the role of individual and household characteristics (in levels) to explain early childbearing remain unchanged. One new insight is that results indicate a positive relationship between mother's education and the likelihood of teenage pregnancy for females. The extended model also brings new insights about the importance of changes over time in household characteristics (area of residence, family structure) and individual characteristics (school achievement, socio-emotional competencies, and aspirations). In fact, the adjusted R-squared obtained for the interacted coefficients model is higher than the obtained for the baseline model (37\% versus $34 \%$, respectively).

We start by uncovering the importance of changes in household socio-economic characteristics and family structure between mid-childhood and mid-adolescence. We find suggestive evidence that migrating from rural to urban areas between ages 8 and 15 have differential effects by gender: the males who migrate from rural to urban areas are more likely to become parents during adolescence while the opposite is true for rural-urban female migrants. Related to the dynamics in the family structure, in the previous sub-section we mentioned that living in a single-parent family at age 8 might be associated with a higher early childbearing probability for females. In this extended specification, we observe that what really makes the difference for females is growing up in a persistently single-parent household between age 8 and 15, a critical developmental phase, transitioning from childhood to adolescence. Coming from a persistently single-parent household (as compared to coming from a household where there were always two parents) seems to increase females' probability of childbearing at age 19 while reduces the probability of childbearing for males by 11 pp. Notably, the estimated coefficient for females (column (iii)) is marginally insignificant, which could result from a loss in precisions due to the small sample size. In fact, the same coefficient is statistically significant in Panel (A), where the sample size is larger. If our 
interpretation is correct, it remains unclear what could drive this gender differential, however this result suggests some form of gender discrimination, whereby males end up receiving more protection once parents separate while females receive less protection. Literature shows that growing up in single parent households and, in particular, exposure to father absence is associated with elevated risk for early sexual activity (e.g., Whitbeck et al, 1999; Afxentiou and Hawley, 1997; Miller and Bingham, 1989) and adolescent pregnancy (Ellis et al., 2003; Manlove, 1998) and in particular the risk is higher for females (Devine et al., 1993). The differences in predictors of male and female sexual activity are possibly related to the way in which sexuality has historically been more culturally acceptable in boys (Devine et al., 1993). An additional relevant factor is the fact that single parent households increase exposure of daughters to their mothers' dating and re-partnering behaviours that may influence daughter's sexual behaviour (Ellis et al., 2003; Devine et al., 1993). The model with constant coefficients by gender also shows evidence of a reduction in the probability of early childbearing by $13 \mathrm{pp}$ when a child's parents had originally separated but either they re-joined or a new couple was formed (compared to coming from a household where there were always two parents).

Looking at changes in individual characteristics between early and mid-adolescence, we find that changes in school achievement (proxied by changes test scores) arise as a protective factor against early childbearing; however, this only occurs for males. Specifically, we observe that improvements in a child's vocabulary test scores between the ages of 12 and 15 are associated with a reduction in the probability of early childbearing for males (while the total estimated coefficient for females is not significantly different from zero).

We also uncover a role for changes in socioemotional skills and child's aspirations for higher education. Both an increase in the level of self-efficacy at age 12 and improvements in the level of self-efficacy between the ages of 12 and 15 are associated to a reduction in the probability of early childbearing when considering males and females together, and it seems to play a stronger protective 
factor for males. In addition, in the model with constant coefficients by gender, a decrease in aspirations (downward aspirations) between ages 12 and 15 is associated with an increase in the probability of early childbearing, by $9 \mathrm{pp}$. This result seems to be driven by females - for whom the point estimate is a ten times larger than that for males.

The new estimates also reiterate the importance of the age of sexual initiation as a key predictive factor for females: having had sex at age 16 or under increases the probability of teenage pregnancy by $55 \mathrm{pp}$. School attendance is not statistically significant in this case, yet as before a comparison of Panel (A) and Panel (B) results for this variable show a dramatic change in the point estimate for females when SHR knowledge and sex behaviours aspects are introduced, suggesting a relationship between school attendance and age of sexual initiation.

\section{Discussion and conclusions}

In this paper we used longitudinal data and insights from the international literature to study potential risk factors of early childbearing in the Peruvian context. To do so, we selected and tested the predictive role of a set of child and household characteristics measured prior to the occurrence of this event (baseline model). We also reported results for an enriched model that takes into account of the role of time changing child and household characteristics (extended model). We exploited the fact that data is available for both males and females to estimate a fully interacted model by gender. Our results are informative of association, not causation; however, the data and empirical strategy used allows to substantially alleviating concerns of reverse causality bias and omitted variable bias that plague studies that use cross-sectional data from standard household surveys.

A first finding is that most risk factors that we are able to identify are either more relevant or, in most cases, only relevant for females. This is consistent with the fact that females are more at risk of early childbearing than males. 
Focusing on the female's sample, we find that early pregnancy is driven mainly by five aspects: (i) household wealth; (ii) family structure; (iii) school achievement and school attendance; (iv) socioemotional competencies and aspirations; and, (iv) age of the first sexual relation.

The negative association between household wealth and teenage pregnancy is well established in the existing literature. However, our results highlight the importance of household wealth measured during mid-childhood as a driving factor for subsequent teenage pregnancy. Although it is tempting to interpret this result in purely economic terms -a higher early-life household income increases the opportunity cost of early pregnancy- this result might also be partially incorporating other unobserved factors, such as household preferences and parents-child interactions.

The role of school attendance and school achievement as protective factors for teenage pregnancy observed is relevant in the Peruvian context, where a meaningful fraction of the population has not completed basic education. In addition, the fact that the age of sexual initiation plays such an important role to predict early childbearing speaks of the importance of incorporating sexual and reproductive health education at the school level. Furthermore, we find that school attendance becomes irrelevant as a risk factor for childbearing once the age of the first sexual relation is taken into account. One way to interpret this result is that dropping out of school during adolescence makes one more likely to have a sexual relationship -and thus, more likely to have a child. This finding would reinforce the notion that school attendance is a protective factor. However, we acknowledge the limitation of our analysis in assessing causality and recognize that it could also be the other way around (i.e. adolescents that have an early sexual initiation might be more prone to drop out of school).

Finally, the extended model provides with additional insights on the importance of time-varying dimensions. While the importance of socio-emotional competencies and aspirations is not patent in our main model, in the extended model, which accounts for changes over time, both changes in selfefficacy and in educational aspirations between early and mid-adolescence arise as important 
predictors. Similarly, as mentioned above, changes in family structure over time do matter. Growing up in a single-parent household during childhood and puberty appears to be associated with a substantially higher probability to become mother during adolescence. On the other hand, changes in household wealth and changes in school performance over time do not seem to play a significant role.

Our analysis is based on longitudinal data. Own calculations show that attrited participants are poorer and more likely to come from rural areas, compared to non-attrited participants. This suggests that the results obtained in this analysis might represent a lower bound of these associations.

What we have, then, is a very rich yet complex picture. The importance of time-varying dimensions suggests policy might play a role to reduce the prevalence of teenage pregnancy. In particular, our analysis allows us to identify some specific areas in which this may be the case. First, policies aimed at improving school completion rates might be effective tools for reducing early pregnancy by increasing the opportunity cost of such a decision. Both education policies and antipoverty programs (e.g., Conditional Cash Transfer programs) are relevant in this respect. These policies should start early and target the critical transition to secondary education.

Second, policies aimed at improving sexual and reproductive health education for adolescents appear to be key in reducing early pregnancy by delaying young people sexual debut. In this area, there is space for both the education and health sectors to work together. Given that school attendance in Peru is near universal up to the first and second grades of secondary school (ages 12 to 13 , approximately), sexual education at school should start early.

Third, the importance of socio-emotional dimensions - the role of changes in socio-emotional competencies, in particular - suggests a space for policies aimed at reinforcing soft skills. Finally, but not least important, the role of improving aspirations in order to increase the willingness to stay at school and avoid risk behaviours that lead to teenage pregnancy. Evidence suggests policies based on role models, mentoring and providing information about the benefits of schooling and the cost of dropping out (Jensen, 2010; La Ferrara et al., 2012; Macours and Vakis, 
2014). A sensible strategy would be to promote these four types of policies simultaneously; they complement each other, and their joint implementation would potentially create a strong safety net for adolescents. 


\section{Tables}

Table 1: Young Lives Peru: Descriptive Statistics

\begin{tabular}{|c|c|c|}
\hline & Mean & Std. Error \\
\hline \multicolumn{3}{|l|}{ Sociodemographic characteristics } \\
\hline Child is female & 0.46 & 0.023 \\
\hline Age & 18.41 & 0.025 \\
\hline YL child's mother was a teenage mother & 0.18 & 0.018 \\
\hline Mother's education - None or Primary School & 0.42 & 0.022 \\
\hline Mother's education - Secondary School & 0.41 & 0.022 \\
\hline Mother's education - Higher education & 0.16 & 0.017 \\
\hline Being at school at age 15 & 0.94 & 0.010 \\
\hline In school age $12-15$ or enrolled only at age 15 & 0.94 & 0.010 \\
\hline Menarche/broken voice by age 12 & 0.48 & 0.023 \\
\hline Urban, age 8 & 0.76 & 0.020 \\
\hline Wealth Index, age 8 & 0.48 & 0.008 \\
\hline In rural area at age 8 and 15 & 0.19 & 0.018 \\
\hline Migrated from urban to rural area, age 8-15 & 0.02 & 0.006 \\
\hline Migrated from rural to urban area, age 8-15 & 0.05 & 0.010 \\
\hline Change in Wealth Index, age 8-15 & 0.13 & 0.007 \\
\hline \multicolumn{3}{|l|}{ Family structure } \\
\hline Child has older brother & 0.49 & 0.023 \\
\hline Child has older sister & 0.45 & 0.023 \\
\hline Number of siblings, age 12 & 2.36 & 0.069 \\
\hline Only one parent in the household, age 8 & 0.16 & 0.017 \\
\hline Change in number of siblings, age $12-15$ & -0.41 & 0.053 \\
\hline Remained in a broken family, age $8-15$ & 0.12 & 0.015 \\
\hline Family became broke, age $8-15$ & 0.12 & 0.015 \\
\hline From broken to re/new-joint family, age 8-15 & 0.04 & 0.009 \\
\hline \multicolumn{3}{|l|}{ School achievement } \\
\hline Standardized PPVT score at age 12 & 0.11 & 0.041 \\
\hline Standardized Math score at age 12 & 0.09 & 0.043 \\
\hline Change in standardized PPVT score, age 12-15 & -0.02 & 0.031 \\
\hline Change in standardized Math score, age 12-15 & 0.01 & 0.041 \\
\hline \multicolumn{3}{|l|}{ Socioemotional competences } \\
\hline Standardized Self-efficacy Index, age 12 & 0.03 & 0.021 \\
\hline Standardized Self-esteem Index, age 12 & -0.02 & 0.020 \\
\hline Change in Self-efficacy Index, age 12-15 & -0.08 & 0.022 \\
\hline Change in Self-esteem Index, age 12-15 & -0.04 & 0.021 \\
\hline
\end{tabular}




\begin{tabular}{lcc} 
& Mean & Std. Error \\
\hline Aspirations & & \\
Child had high aspiration at age 12 & 0.79 & 0.018 \\
Persistently low education aspirations, age 12-15 & 0.07 & 0.012 \\
Downward educational aspirations, age 12-15 & 0.11 & 0.014 \\
Upward educational aspirations, age 12-15 & 0.13 & 0.016 \\
& & \\
Expectations & & \\
Parent expectation: age to have a child & 28.18 & 0.178 \\
Parent expectation: age to get married & 27.31 & 0.169 \\
Parent expectation: age to leave education & 22.14 & 0.141 \\
& & \\
Sex knowledge and sexual behavior & & \\
Standardized Sex Knowledge Index & 0.07 & 0.047 \\
Had sex before the age of 16 & 0.35 & 0.022 \\
Unprotected sex, age 15 & 0.07 & 0.012 \\
Note: The table reports some descriptive statistics for the balanced sample of children observed across all rounds and with non-missing data, 483 \\
individuals
\end{tabular}


Table 2: Prevalence of teenage fertility in Young Lives

\begin{tabular}{|c|c|c|c|c|c|c|c|}
\hline & \multirow[t]{2}{*}{ Total } & \multicolumn{2}{|c|}{ By gender } & \multicolumn{2}{|c|}{$\begin{array}{c}\text { By area of } \\
\text { location }\end{array}$} & \multicolumn{2}{|c|}{ By wealth } \\
\hline & & Female & Male & Rural & Urban & Bottom & Top \\
\hline Has a child & 0.12 & 0.21 & $0.05^{* * *}$ & 0.13 & 0.12 & 0.15 & 0.12 \\
\hline No. of children born & 0.13 & 0.24 & $0.05 * * *$ & 0.14 & 0.13 & 0.16 & 0.14 \\
\hline Has one child & 0.11 & 0.18 & $0.04 * * *$ & 0.12 & 0.10 & 0.13 & 0.10 \\
\hline Has more than one child & 0.01 & 0.03 & $0.00 *$ & 0.01 & 0.02 & 0.02 & 0.02 \\
\hline Observations & 483 & 221 & 262 & 102 & 381 & 110 & 205 \\
\hline
\end{tabular}


Table 3: Linear Probability Model estimates on the risk factors of early childbearing

\begin{tabular}{|c|c|c|c|c|c|c|c|c|}
\hline \multicolumn{5}{|c|}{ Panel (A) } & \multicolumn{4}{|c|}{ Panel (B) } \\
\hline & (i) & \multicolumn{2}{|c|}{ (ii) } & \multirow[b]{2}{*}{$\begin{array}{c}\text { (iii) } \\
\text { Common } \\
\text { coefficient } \\
+ \\
\text { interaction } \\
\text { coefficient }\end{array}$} & (i) & \multicolumn{2}{|c|}{ (ii) } & \multirow[b]{2}{*}{$\begin{array}{c}\text { (iii) } \\
\text { Common } \\
\text { coefficient } \\
+ \\
\text { interaction } \\
\text { coefficient }\end{array}$} \\
\hline & All & $\begin{array}{l}\text { Common } \\
\text { coefficient }\end{array}$ & $\begin{array}{l}\text { Interaction } \\
\text { Female } \\
\text { dummy }\end{array}$ & & All & $\begin{array}{l}\text { Common } \\
\text { coefficient }\end{array}$ & $\begin{array}{l}\text { Interaction } \\
\text { Female } \\
\text { dummy }\end{array}$ & \\
\hline Female & $\begin{array}{c}0.163 * * * \\
(0.037)\end{array}$ & $\begin{array}{c}0.692 \\
(0.875)\end{array}$ & & & $\begin{array}{c}0.222 * * * \\
(0.044)\end{array}$ & $\begin{array}{l}0.771 \\
(0.827)\end{array}$ & & \\
\hline Age & $\begin{array}{c}0.068 * * * \\
(0.022) \\
\end{array}$ & $\begin{array}{c}0.076^{* *} \\
(0.034) \\
\end{array}$ & $\begin{array}{l}-0.013 \\
(0.055)\end{array}$ & $\begin{array}{c}0.063 \\
(0.038)\end{array}$ & $\begin{array}{c}0.066 * * \\
(0.029) \\
\end{array}$ & $\begin{array}{l}0.080 * * \\
(0.037) \\
\end{array}$ & $\begin{array}{r}-0.043 \\
(0.055)\end{array}$ & $\begin{array}{c}0.037 \\
(0.043)\end{array}$ \\
\hline \multicolumn{9}{|c|}{ Factors measured during mid-childhood or time invariant } \\
\hline \multicolumn{9}{|c|}{ Household sociodemographic characteristics } \\
\hline $\begin{array}{l}\text { Mother's education } \\
\text { - secondary } \\
\text { Mother's education } \\
\text { - higher education } \\
\text { Wealth Index, age } 8\end{array}$ & $\begin{array}{c}0.004 \\
(0.034) \\
-0.021 \\
(0.056) \\
-0.207 \\
(0.164) \\
\end{array}$ & $\begin{array}{c}-0.042 \\
(0.036) \\
-0.022 \\
(0.068) \\
0.002 \\
(0.137) \\
\end{array}$ & $\begin{array}{c}0.146 * \\
(0.074) \\
0.07 \\
(0.086) \\
-0.501 * * \\
(0.233) \\
\end{array}$ & $\begin{array}{c}0.104 \\
(0.069) \\
0.048 \\
(0.078) \\
-0.500 * \\
(0.238) \\
\end{array}$ & $\begin{array}{c}0.009 \\
(0.039) \\
0.015 \\
(0.064) \\
-0.229 * * \\
(0.108) \\
\end{array}$ & $\begin{array}{c}-0.03 \\
(0.037) \\
-0.013 \\
(0.074) \\
0.022 \\
(0.116) \\
\end{array}$ & $\begin{array}{c}0.091 \\
(0.076) \\
0.111 \\
(0.076) \\
-0.653 * * * \\
(0.18) \\
\end{array}$ & $\begin{array}{c}0.061 \\
(0.073) \\
0.098 \\
(0.070) \\
-0.631 * * * \\
(0.140) \\
\end{array}$ \\
\hline \multicolumn{9}{|l|}{ Family structure } \\
\hline $\begin{array}{l}\text { Child has older } \\
\text { brother } \\
\text { Number of siblings, } \\
\text { age } 12 \\
\text { Only one parent in } \\
\text { household, age } 8\end{array}$ & $\begin{array}{c}0.034 \\
(0.032) \\
-0.016 \\
(0.01) \\
0.002 \\
(0.044) \\
\end{array}$ & $\begin{array}{l}-0.002 \\
(0.038) \\
-0.006 \\
(0.013) \\
-0.060 * \\
(0.031) \\
\end{array}$ & $\begin{array}{l}0.091 \\
(0.066) \\
-0.021 \\
(0.027) \\
0.157 * \\
(0.085) \\
\end{array}$ & $\begin{array}{c}0.089 \\
(0.055) \\
-0.027 \\
(0.021) \\
0.097 \\
(0.084) \\
\end{array}$ & $\begin{array}{c}0.022 \\
(0.031) \\
-0.020 * * \\
(0.01) \\
-0.054 \\
(0.042) \\
\end{array}$ & $\begin{array}{c}-0.019 \\
(0.041) \\
-0.012 \\
(0.014) \\
-0.093^{*} * \\
(0.04) \\
\end{array}$ & $\begin{array}{l}0.105^{*} \\
(0.06) \\
0.005 \\
(0.027) \\
0.144^{*} \\
(0.083) \\
\end{array}$ & $\begin{array}{c}0.086^{*} \\
(0.032) \\
-0.007 \\
(0.018) \\
0.051 \\
(0.067) \\
\end{array}$ \\
\hline \multicolumn{9}{|c|}{ Factors measured during early adolescence } \\
\hline \multicolumn{9}{|c|}{ School achievement } \\
\hline $\begin{array}{l}\text { Std PPVT score at } \\
\text { age } 12 \\
\text { Std Math score at } \\
\text { age } 12\end{array}$ & $\begin{array}{c}-0.024 \\
(0.021) \\
0.006 \\
(0.023) \\
\end{array}$ & $\begin{array}{c}0.000 \\
(0.020) \\
-0.003 \\
(0.023) \\
\end{array}$ & $\begin{array}{c}-0.067 * \\
(0.034) \\
0.008 \\
(-0.046) \\
\end{array}$ & $\begin{array}{c}-0.067 * * \\
(0.029) \\
0.005 \\
(0.043) \\
\end{array}$ & $\begin{array}{l}-0.029 \\
(0.024) \\
-0.001 \\
(0.026) \\
\end{array}$ & $\begin{array}{c}-0.008 \\
(0.024) \\
0.002 \\
(0.027) \\
\end{array}$ & $\begin{array}{c}-0.049 \\
(0.032) \\
-0.03 \\
(0.047) \\
\end{array}$ & $\begin{array}{l}-0.058 \\
(0.035) \\
-0.028 \\
(0.043) \\
\end{array}$ \\
\hline \multicolumn{9}{|c|}{ Socioemotional competences, aspirations and expectations } \\
\hline $\begin{array}{l}\text { Std Self-efficacy } \\
\text { Index, age } 12 \\
\text { Child had high } \\
\text { aspiration at age } 12\end{array}$ & $\begin{array}{c}0.005 \\
(0.032) \\
0.056 \\
(0.036)\end{array}$ & $\begin{array}{c}0.024 \\
(0.023) \\
0.04 \\
(0.026)\end{array}$ & $\begin{array}{c}-0.016 \\
(0.066) \\
0.033 \\
(0.078)\end{array}$ & $\begin{array}{c}0.008 \\
(0.065) \\
0.073 \\
(0.074)\end{array}$ & $\begin{array}{c}-0.008 \\
(0.043) \\
0.04 \\
(0.043)\end{array}$ & $\begin{array}{c}0.001 \\
(0.033) \\
0.036 \\
(0.024)\end{array}$ & $\begin{array}{l}0.015 \\
(0.077) \\
-0.003 \\
(0.072)\end{array}$ & $\begin{array}{c}0.016 \\
(0.071) \\
0.034 \\
(0.064)\end{array}$ \\
\hline $\begin{array}{l}\text { Parent expectation: } \\
\text { age to have a child }\end{array}$ & $\begin{array}{c}0.005 \\
(0.007) \\
\end{array}$ & $\begin{array}{c}0.000 \\
(0.008) \\
\end{array}$ & $\begin{array}{c}0.012 \\
(0.011) \\
\end{array}$ & $\begin{array}{c}0.011 \\
(0.009) \\
\end{array}$ & $\begin{array}{c}0.007 \\
(0.006) \\
\end{array}$ & $\begin{array}{c}0.008 \\
(0.005) \\
\end{array}$ & $\begin{array}{c}-0.01 \\
(0.015) \\
\end{array}$ & $\begin{array}{l}-0.001 \\
(0.014) \\
\end{array}$ \\
\hline \multicolumn{9}{|l|}{ Biological factors } \\
\hline $\begin{array}{l}\text { Menarche/broken } \\
\text { voice by age } 12\end{array}$ & $\begin{array}{l}-0.006 \\
(0.023) \\
\end{array}$ & $\begin{array}{l}-0.011 \\
(0.030) \\
\end{array}$ & $\begin{array}{c}0.047 \\
(0.072) \\
\end{array}$ & $\begin{array}{c}0.036 \\
(0.060) \\
\end{array}$ & $\begin{array}{l}-0.021 \\
(0.026) \\
\end{array}$ & $\begin{array}{c}0.003 \\
(0.025) \\
\end{array}$ & $\begin{array}{l}-0.005 \\
(0.06) \\
\end{array}$ & $\begin{array}{l}-0.002 \\
(0.049) \\
\end{array}$ \\
\hline \multicolumn{9}{|c|}{ Factors measured during mid adolescence } \\
\hline \multicolumn{9}{|c|}{ School enrolment } \\
\hline $\begin{array}{l}\text { Being at school at } \\
\text { age } 15\end{array}$ & $\begin{array}{c}-0.146 * * \\
(0.069)\end{array}$ & $\begin{array}{l}-0.022 \\
(0.063)\end{array}$ & $\begin{array}{l}-0.295^{*} \\
(0.152)\end{array}$ & $\begin{array}{c}-0.317 * * \\
(0.139)\end{array}$ & $\begin{array}{l}-0.074 \\
(0.072)\end{array}$ & $\begin{array}{l}-0.074 \\
(0.075)\end{array}$ & $\begin{array}{c}0.07 \\
(0.163)\end{array}$ & $\begin{array}{l}-0.004 \\
(0.127)\end{array}$ \\
\hline \multicolumn{9}{|c|}{ Sexual knowledge and behavior } \\
\hline $\begin{array}{l}\text { Had sex before by } \\
\text { age } 17\end{array}$ & & & & & $\begin{array}{c}0.246 * * * \\
(0.049)\end{array}$ & $\begin{array}{l}0.066^{*} \\
(0.035)\end{array}$ & $\begin{array}{l}0.485^{* * * *} \\
(0.06)\end{array}$ & $\begin{array}{c}0.551 * * * \\
(0.077)\end{array}$ \\
\hline Observations & & & 83 & & & & 20 & \\
\hline Adjusted R-squared & 0.096 & & 0.116 & & 0.21 & & 0.339 & \\
\hline
\end{tabular}

Note: The table reports the estimates of a linear probability model with cluster fixed effect, robust standard errors, clustered at the cluster level. * $<<0.1 * *$ $\mathrm{p}<0.05 * * * \mathrm{p}<0.01$. We additionally control for the following variables: child has an older sister, urban (at age 8), YL's child mother was a teenage mother, parents' expectation for the age to get married, parents' expectation for the age to leave full-time education, standardized Self-esteem Index (age 12), standardized Sex Knowledge Index (age 15) and teen has had unprotected sex (age 15). Column (i) reports results for the constant coefficients model, Column (ii) reports results for the interacted coefficients model (both the common coefficient and the interaction with the female dummy are reported); Column (iii) reports the total estimated coefficients for the female sample implied from Column (ii). 
Table 4. Linear Probability Model estimates of interaction term on changes in initial conditions

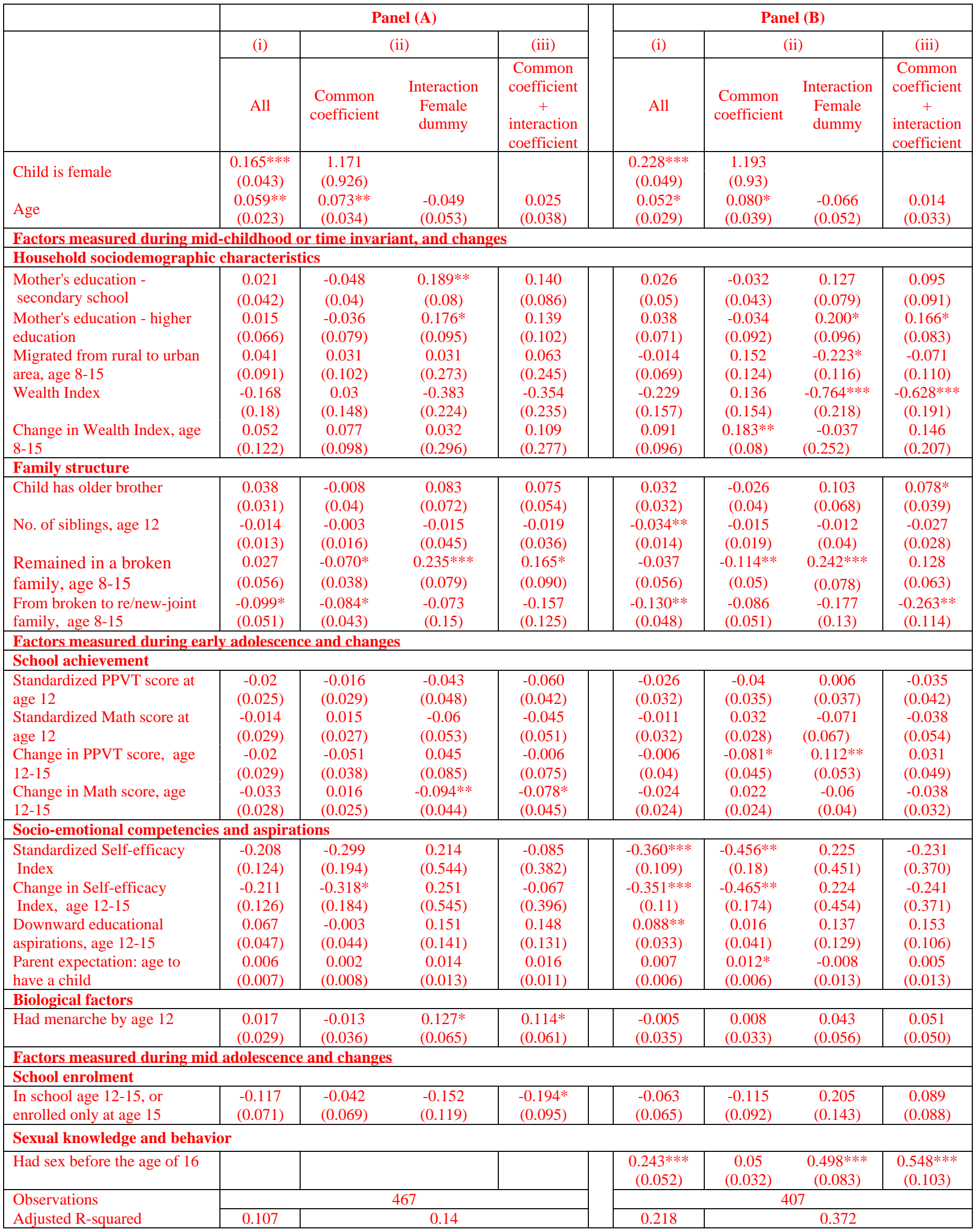


Note: The table reports the estimates of a linear probability model with cluster fixed effect, robust standard errors, clustered at the cluster level. $*$ p $<0.1 * *$ $\mathrm{p}<0.05 * * * \mathrm{p}<0.01$. We additionally control for the following variables: child has an older sister, YL's child mother was a teenage mother, parents'

expectation for the age to get married, parents' expectation for the age to leave full-time education, standardized Self-esteem Index (age 12), standardized Sex Knowledge Index (age 15), teen has had unprotected sex (age 15), lived in rural area at age 8 and 15, migrated from urban to rural area (age 8-15), change in number of siblings (12-15), family became broke (age 8-15), persistently low education aspirations (age 12-15), upward educational aspirations (age 12-15), change in standardized sex knowledge index. Column (i) reports results for the constant coefficients model; Column (ii) reports results for the interacted coefficients model (both the common coefficient and the interaction with the female dummy are reported); Column (iii) reports the total estimated coefficients for the female sample implied from Column (ii). 


\section{References}

Acharya, D., R. Bhattarai, R. Poobalan, E. van Teijlingen, and G. Chapman (2010). Factors associated with teenage pregnancy in South Asia: a systematic review. Health Science Journal $4(1), 3-14$.

Afxentiou, D., \& Hawley, C. B. (1997). Explaining female teenagers' sexual behavior and outcomes: A bivariate probit analysis with selectivity correction. Journal of Family and Economic Issues, 18(1), 91-106.

Ananat, E. O. and D. M. Hungerman (2012). The Power of the Pill for the Next Generation: Oral Contraception's Effects on Fertility, Abortion and Maternal \& Child Characteristics. The review of economics and statistics 94(1), 37-51.

Ashcraft, A. and K. Lang (2006). The Consequences of Teenage Childbearing. Working Paper 12485, National Bureau of Economic Research.

Azevedo, J. P., M. Favara, S. E. Haddock, L. F. Lopez-Calva, M. Muller, and E. Perova (2012). Teenage Pregnancy and Opportunities in Latin America and the Caribbean. On Teenage Fertility Decisions, Poverty and Economic Achievement. World Bank, Washington, DC. https://openknowledge.worldbank.org/handle/10986/16978 License: CC BY 3.0 IGO.

Brewster, K., Billy, J. and Grady, W. (1993). Social Context and Adolescent Behavior: The Impact of Community on the Transition to Sexual Activity. Social Forces 71(3), 713-740.

Briones, K. (2017). 'How Many Rooms Are There in Your House?' Constructing the Young Lives Wealth Index. Young Lives Technical Note 43. Oxford: Young Lives.

De Genna, N., Larkby, C., Cornelius, M (2011). Pubertal Timing and Early Sexual Intercourse in the Offspring of Teenage Mothers. Journal of Youth and Adolescence 10(10), 1315-1328.

Devine, D., Long, P., \& Forehand, R. (1993). A prospective study of adolescent sexual activity: Description, correlates, and predictors. Advances in Behaviour Research and Therapy, 15(3), 185-209.

Ellis, B. J., Bates, J. E., Dodge, K. A., Fergusson, D. M., John Horwood, L., Pettit, G. S., \& Woodward, L. (2003). Does father absence place daughters at special risk for early sexual activity and teenage pregnancy?. Child development, 74(3), 801-821.

Escobal, J. and E. Flores (2008). An Assessment of the Young Lives Sampling Approach in Peru. Young Lives Technical Note 3.

Francesconi, M. (2008). Adult Outcomes for Children of Teenage Mothers. Scandinavian Journal of Economics 110(1), 93-117.

Geronimus, A. T., S. Korenman, and M. M. Hillemeier (1994). Does Young Maternal Age Adversely Affect Child Development? Evidence from Cousin Comparisons in the United States. Population and Development Review 20(3), 585-609.

Hobcraft, J. and Kiernan, K. (2001) Childhood poverty, early motherhood and adult social exclusion. British Journal of Sociology 52(3), 495-517.

Imamura, M., Tucker, J., Hannaford, P., Oliveira da Silva, M., Astin, M., Wyness, L., Bloemenkamp, K., Jahn, A., Karro, H., Olsen, J. (2007). Factors associated with teenage pregnancy in the European Union countries: a systematic review. Journal of Public Health $17(6), 630-636$.

Kane, T. J. and D. Staiger (1996). Teen Motherhood and Abortion Access. The Quarterly Journal of Economics 111(2), 467-506.

La Ferrara E., Chong, A., Duryea, S. (2012), "Soap Operas and Fertility: Evidence from Brazil”, American Economic Journal: Applied Economics, (pp. 1-31). 
Levine, J. A., H. Pollack, and M. E. Comfort (2001). Academic and Behavioral Outcomes Among the Children of Young Mothers. Journal of Marriage and Family 63(2), 355-369.

Lopez Turley, R. (2003). Are Children of Young Mothers Disadvantaged because of Their Mother's Age or Family Background? Child Development 74 (2), 465-474.

Lundberg, S. and R. D. Plotnick (1995). Adolescent Premarital Childbearing: Do Economic Incentives Matter? Journal of Labor Economics 13(2), 177-200.

Macours K., Vakis R. (2014) “Changing Households' Investment Behavior through Social Interactions with Local Leaders: Evidence from a Randomized Transfer Program”, Economic Journal, 124 (576): 607-33.

Magadi, M. (2017). Multilevel determinants of teenage childbearing in Sub-Saharan Africa in the context of hiv/aids. Health and Place 46, 37-48.

Maness, S., Buhi, E., Daley, E., Baldwin, J., Kromrey, J. (2016) Social Determinants of Health and Adolescent Pregnancy: An Analysis from the National Longitudinal Study of Adolescent to Adult Health. Journal of Adolescent Health 58(6), 636-643.

Manlove, J. (1998). The influence of high school dropout and school disengagement on the risk of school-age pregnancy. Journal of research on adolescence, 8(2), 187-220.

Margherita, G., Troisi, G., Tessitore, F. and Gargiulo, A. (2017). Teen mothers who are daughters of teen mothers: Psychological intergenerational dimensions of early motherhood. Children and Youth Services Review 83, 294-301.

Miller, B. C., \& Bingham, C. R. (1989). Family configuration in relation to the sexual behavior of female adolescents. Journal of Marriage and the Family, 499-506.

Nüñez, J. and C. E. Flórez (2001). Teenage Childbearing in Latin American Countries. IDB Working Paper No. 147, Inter-American Development Bank.

Plotnick, R. D. (1992). The Effects of Attitudes on Teenage Premarital Pregnancy and its Resolution. American Sociological Review 57(6), 800-811.

Plotnick, R. D. (1993). The Effect of Social Policies on Teenage Pregnancy and Childbearing. Families in Society 74(6), 324-328.

Plotnick, R. D., I. Garfinkel, S. S. McLanahan, and I. Ku (2007). The Impact of Child Support Enforcement Policy on Nonmarital Childbearing. Journal of Policy Analysis and Management 26(1), 79-98.

Pradhan, R., K. Wynter, and J. Fisher (2015). Factors associated with pregnancy among adolescents in low-income and lower middle-income countries: a systematic review. Journal of Epidemiology Community Health 69, 918-924.

Quinlivan, J., Tan, L., Steele, A. and Black, K (2004). Impact of demographic factors, early family relationships and depressive symptomatology in teenage pregnancy. Australian and New Zealand Journal of Psychiatry 38, 197-203.

Rascon-Ramirez, E. G. (2014). Teenage Pregnancy and Motherhood in England: Do parents' educational expectations matter? Conference paper, University of Essex. Institute for Social and Economic Research (ISER).

Jensen, R. (2010). "The (Perceived) Returns to Education and the Demand for Schooling", Quarterly Journal of Economics, 25(2), p. 515-548.

Were, M. (2007). Determinants of teenage pregnancies: the case of Busia district in Kenya. Economics and Human Biology 5, 322-339.

Whitbeck, L. B., Yoder, K. A., Hoyt, D. R., \& Conger, R. D. (1999). Early adolescent sexual activity: A developmental study. Journal of Marriage and the Family, 934-946 
Yorke, L. and M.J. Ogando Portela (2018), Psychosocial Scales in the Young Lives Round 4 Survey: Selection, Adaptation and Validation, Young Lives Technical Note, No. 45.

Young, T, Turner, J., George, D. and Young, M. (2004). Examining external and internal poverty as antecedents of teen pregnancy. American Journal of Health Behavior 28(4), 361-373. 